\title{
Some observations on ticks (Acari: Ixodidae) infesting sheep in River Nile Province of Northern Sudan
}

\author{
B.M. AHMED ${ }^{1}$, A.M. EL HUSSEIN ${ }^{2 *}$ and A.O. EL KHIDER ${ }^{1}$
}

\begin{abstract}
AHMED, B.M., EL HUSSEIN, A.M. \& EL KHIDER, A.O. 2005. Some observations on ticks (Acari: Ixodidae) infesting sheep in River Nile Province of Northern Sudan. Onderstepoort Journal of Veterinary Research, 72:239-243

Five species of ixodid ticks were found in a cross-sectional survey in which 200 sheep were examined for ticks in River Nile Province, Sudan. Hyalomma anatolicum anatolicum was the predominant species (73.6\%), whereas ticks belonging to the Rhipicephalus sanguineus group (14.7\%), Rhipicephalus evertsi evertsi (9.1\%), Rhipicephalus simus (2\%) and Hyalomma dromedarii (0.5\%) were also found. The mean tick load was 11.2 per animal. In a subsequent longitudinal survey ticks were collected on a monthly basis from eight sentinel sheep that were introduced into the area. It was found that $H$. a. anatolicum almost disappeared during the hot period between April and August, whereas it's highest numbers were present in winter between November and February. It is concluded that there is only one generation of $H$. a. anatolicum per year, which may explain the yearround appearance of clinical cases of malignant ovine theileriosis indicating endemic instability of this disease in River Nile Province.
\end{abstract}

Keywords: Northern Sudan, sheep, survey, ticks

\section{INTRODUCTION}

River Nile Province in northern Sudan covers an area of about $124000 \mathrm{~km}^{2}$. The province has borders with Egypt to the north, the Red Sea and Kassala Provinces to the east, Khartoum Province to the south and the Northern Province to the west. The numbers of animals in River Nile Province are modest compared to other regions of the country. Sheep and goats constitute the majority of the animal wealth with an estimated 953000 and 1149000

* Author to whom correspondence is to be directed. E-mail: abdelhussein@hotmail.com

1 Faculty of Education, Nile Valley University, P.O. Box 136 Atbara, Sudan

2 Central Veterinary Research Laboratories, P.O. Box 8067 Alamarat, Khartoum, Sudan

Accepted for publication 21 June 2005-Editor head, respectively (Anon. 2002). They are usually raised as small mixed flocks along the Nile River and the banks of the seasonal Atbara River.

River Nile Province is part of the so-called diseasefree zone of northern Sudan, where major contagious diseases such as peste des petits ruminants, sheep pox, and foot-and-mouth disease are rare. The area is used for fattening sheep and as a quarantine of animals for export before they are shipped to neighbouring countries. However, clinical cases of malignant ovine theileriosis are reported throughout the year in this area, but are most prevalent during the hot and dry season between March and May (El Ghali \& El Hussein 1995). Very little work has been carried out on the ticks infesting small ruminants in the Sudan (Osman 1997). We therefore conducted the present study to shed some light on the tick fauna in this part of the country. 


\section{MATERIALS AND METHODS}

\section{Study area}

River Nile Province lies within the tropical zone and occupies both desert and semi-desert areas. The most important climatic feature of the Province is the occurrence of a long dry season extending for approximately eight months from November to June, while the rainy season is restricted to the months of July to October with rainfall occurring mostly in August. The average annual rainfall ranges between zero in the northern part of the province, to around $100 \mathrm{~mm}$ in the southern part. The hot season extends from March to October with May and June usually being the hottest months when daily maximum temperatures can be well above $40^{\circ} \mathrm{C}$. The cold dry season extends from November to February, January being the coldest month.

The vegetation of the state is poor and sparse. In the desert zones, it is virtually absent except along the banks of the Nile River and water courses where ephemeral herbs and grasses occur after the occasional rainfall. In the basins and along the Nile banks Acacia spp. are found. In the southern part the vegetation is typical of a semi-desert region, and is dominated by Acacia toritilis. Other trees are Acacia seyal, Balanites aegyptica and Ziziphus spinachristi. Ground shrubs include Calotropis procera, Caparis decidua, Lyptadenia pyrotechnica and Cassia spp. The dominant grasses are Aristida mutabilis and Cympopogon nervatus (Anderson 1948, Harrison \& Jackson 1958).

\section{Cross-sectional survey}

Whole body tick collections were made from 200 randomly selected sheep in 15 different localities in the southern part of River Nile Province. The ticks were preserved in $70 \%$ ethanol and identified according to the keys provided by Hoogstraal (1956).

\section{Longitudinal survey}

Eight indigenous sheep between 6-12 months old were obtained from a local market and subsequently introduced into El Akad village, located at the east bank of the Nile River near Atbara. The animals were monitored as sentinel animals to study the dynamics of the local tick population. The sheep were kept as one flock under traditional husbandry adjacent to village herds of cattle and flocks of sheep and goats. During daytime they were allowed to mix with village animals while grazing on residual agricultural crops grown along the banks of the Nile River. Additional feed was provided to the animals upon return to their sheds at sunset.

The sheep were completely deticked at monthly intervals for 18 months between October 1996 and March 1998. The ticks were preserved in $70 \%$ ethanol, labelled and identified as above.

\section{RESULTS}

\section{Cross-sectional survey}

An average of 11.2 ticks per animal were collected from the 200 sheep. The majority of the ticks (1506) were adults and 723 were nymphs; only four larvae were collected (Table 1).

The range and mean tick load per animal of $H$. a. anatolicum was found to be significantly higher $(P<$ $0.001)$ than that of all other tick species together. Males usually outnumbered females except for $R$. simus (eight males and 11 females). Hyalomma a. anatolicum was found on $59.5 \%$ of the animals examined, whereas $R$. sanguineus group, $R$. e. evertsi and $R$. simus were found on $24 \%, 31.5 \%$ and $15.5 \%$ of the animals, respectively. Hyalomma dromedarii was found on only two animals (1\%) (Table 1).

\section{Longitudinal survey}

Only $H$. a. anatolicum and $R$. sanguineus group ticks were found on sentinel sheep at El Akad village. Hyalomma a. anatolicum was the predominant species, comprising $92 \%$ of the total number of ticks collected, while $R$. sanguineus group ticks represented only $8 \%$. Only one female of $R$. e. evertsi was collected. With the exception of one Rhipicephalus spp. nymph, all immature ticks collected (1963 nymphs and 1673 larvae) were Hyalomma ticks.

The seasonal activity of $H$. a. anatolicum ticks is shown in Table 2 and Fig. 1. Adults of $H$. a. anatolicum were found to be active throughout the year, but they were most prevalent during the period September to March (late rainy season to early summer). Peak infestations occurred during November and a second peak occurred in March. A drastic decrease in tick numbers was observed from May to August (mid-summer to early rainy season). The mean $H$. a. anatolicum tick load was relatively high (11.6) during winter (November to February) decreasing to 10.6 during summer (March-June) with a further decrease to 7.3 during the rainy season (July to October). A significant difference $(P<0.05)$ in mean tick load was found only between winter and the rainy season. 
B.M. AHMED, A.M. EL HUSSEIN \& A.O. EL KHIDER

TABLE 1 Prevalence of different tick species infesting sheep in River Nile Province. Figures in parenthesis represent numbers of animals infested

\begin{tabular}{|l|l|l|l|l|l|}
\hline Tick species & \multirow{2}{*}{$\begin{array}{l}\text { No. of adults } \\
\text { collected }\end{array}$} & Male/female & \multicolumn{2}{l|}{$\begin{array}{l}\text { Percentage } \\
\text { of total } \\
\text { tick burden }\end{array}$} & \multicolumn{2}{|l|}{ Average no. of tick/animal } \\
\cline { 3 - 5 } & & & 73.57 & $1-60$ & Rean \pm SE \\
\hline H. a. anatolicum & $1108(119)$ & $766 / 342$ & 14.74 & $1-22$ & $9.31 \pm 0.97$ \\
R. sanguineus group & $222(48)$ & $170 / 52$ & 9.10 & $4.63 \pm 0.70$ \\
R. evertsi evertsi & $137(63)$ & $97 / 40$ & 2.06 & $1-5$ & $2.17 \pm 0.19$ \\
R. simus & $31(17)$ & $8 / 11$ & 0.53 & $1-7$ & $1.82 \pm 0.30$ \\
H. dromedarii & $8(2)$ & $5 / 3$ & & $4.00 \pm 3.00$ \\
\hline
\end{tabular}

TABLE 2 Monthly variations of $H$. a. anatolicum found on sheep at El-Akad area

\begin{tabular}{|c|c|c|c|c|}
\hline \multirow{2}{*}{ Month } & \multicolumn{2}{|l|}{ Adults } & \multicolumn{2}{|c|}{ Immatures (larvae and nymphae) } \\
\hline & Total & Mean & Total & Mean \\
\hline Oct. 1996 & 31 & 3.9 & 58 & 7.3 \\
\hline Nov. & 43 & 5.4 & 572 & 71.5 \\
\hline Dec. & 97 & 12.1 & 28 & 3.5 \\
\hline Jan. & 91 & 11.4 & 16 & 2 \\
\hline Feb. & 10 & 1.3 & 181 & 22.6 \\
\hline Mar. & 107 & 13.4 & 4 & 0.5 \\
\hline Apr. & 55 & 6.9 & 0 & 0 \\
\hline May & 1 & 0.1 & 0 & 0 \\
\hline June & 11 & 1.4 & 0 & 0 \\
\hline July & 14 & 1.8 & 0 & 0 \\
\hline Aug. & 7 & 0.9 & 0 & 0 \\
\hline Sep. & 91 & 11.4 & 331 & 41.3 \\
\hline Oct. & 121 & 15.1 & 570 & 71.3 \\
\hline Nov. & 163 & 20.4 & 368 & 46 \\
\hline Dec. & 125 & 15.6 & 135 & 16.9 \\
\hline Jan. & 113 & 14.1 & 766 & 95.4 \\
\hline Feb. & 100 & 12.5 & 189 & 23.6 \\
\hline Mar. 1998 & 251 & 31.4 & 112 & 14 \\
\hline Total & 1431 & 9.9 & 3330 & 23.1 \\
\hline
\end{tabular}

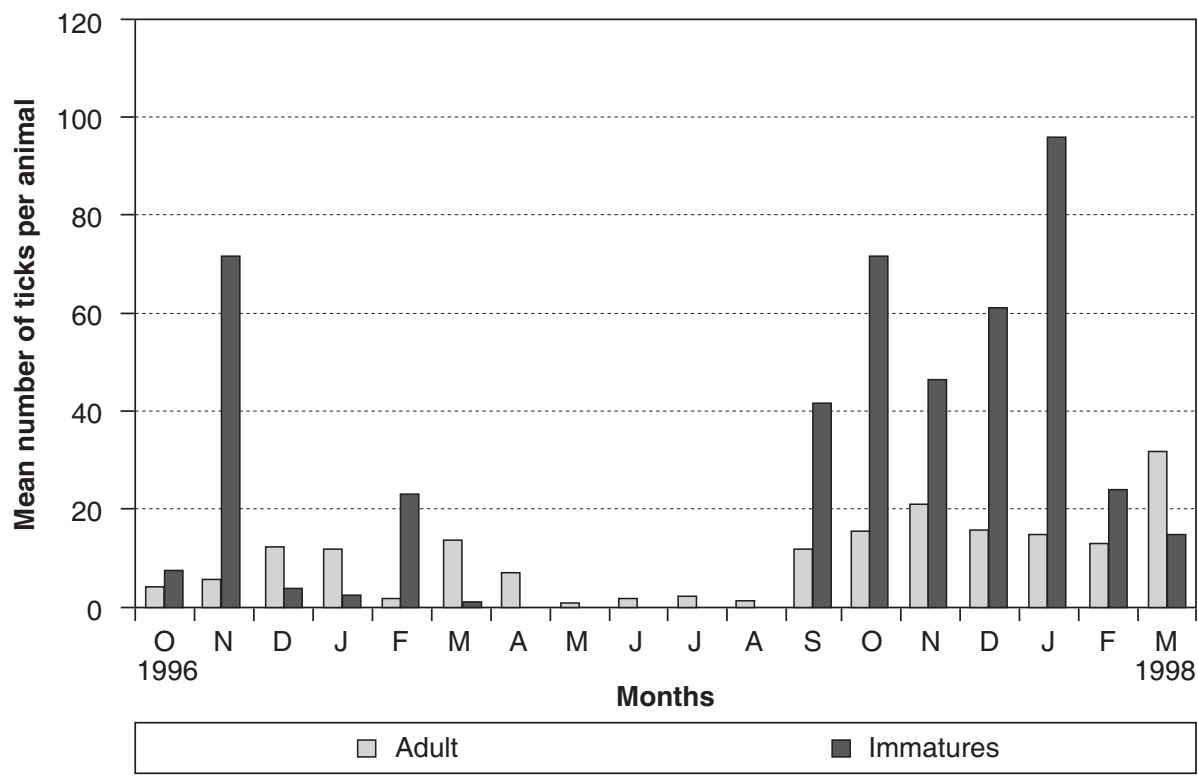

FIG. 1 The monthly activity of adults and immature stages of Hyalomma a. anatolicum on sheep in El-Akad area 
The immature stages of Hyalomma spp. (presumably $H$. a. anatolicum) showed a pronounced activity during the same period as adult $H$. a. anatolicum (September to March), but they completely disappeared from the animals between April and August (Fig. 1). In general, males of $H$. a. anatolicum outnumbered female ticks throughout the study period (Table 1).

The mean number of $H$. a. anatolicum ticks per animal decreased during months when the maximum temperature exceeded $40^{\circ} \mathrm{C}$ and also in months when the minimum temperature was below $15^{\circ} \mathrm{C}$ (Table 2, Fig. 1).

\section{DISCUSSION}

Thirty-five species of ticks are known to infest sheep and goats in the Sudan (Osman 1997). During the present investigation, five species of ticks were found to infest sheep in River Nile Province, Northern Sudan. These were (in order of abundance), $H$. a. anatolicum, $R$. sanguineus group, $R$. e. evertsi, $R$. simus and $H$. dromedarii. These species were previously reported on sheep from northern Sudan (Hoogstraal 1956) and from Khartoum Province in central Sudan (Jongejan, Zivkovic, Pegram, Tatchell, Fison, Latif \& Paine 1987).

In general, the mean number of ticks per sheep (11.2) was comparable to those reported by Jongejan et al. (1987) (11.5) and Karrar, Kaiser \& Hoogstraal (1963) (13.0), and higher than the 6.7 reported by Mohamed (1999). Jongejan et al. (1987) indicated that the mean tick load varied between 4.2 in Khartoum Province and 15.9 in Blue Nile Province, where more favourable conditions for survival and reproduction of ticks exist. It is clear that the ecological conditions of River Nile province do not allow for survival and reproduction of several other species that do infest sheep e.g. Amblyomma lepidum, Amblyomma variegatum, Hyalomma spp. and Boophilus spp. present in other regions of the country (Karrar et al. 1963; Osman, El Hussein, Ahmed \& Abdulla 1982).

Male ticks represented the majority for all species collected except for $R$. simus. This confirms the results of Jongejan et al. (1987) who reported that male ticks usually outnumbered females of all species infesting cattle except for Boophilus spp. in central and southern Sudan.

Hyalomma a. anatolicum has been described by many workers as a tick adapted to harsh environments (Hoogstraal 1956; Jongejan et al. 1987). This xerophilic species is the most abundant tick in Khartoum Province (desert scrub zone in central Sudan) (Jongejan et al. 1987; Mohamed 1999). Further south, its distribution was limited to north of latitude $14^{\circ}$. Hyalomma impeltatum, on the other hand, is the most common tick of sheep in the arid zone of Kordofan (western Sudan) (Osman et al. 1982). In the present study, $H$. a. anatolicum appeared to be the most successful tick on sheep in this arid zone. This may be explained by the fact that it can easily adapt to man-made microenvironments, which are to be found in the agricultural areas along the Nile River banks. This may also explain recent reports of this species in areas further south in Blue and White Nile Provinces where intensive farming using indigenous and crossbred animals is now practiced (Jongejan et al. 1987; El Imam 2003).

Jongejan et al. (1987) indicated that different species of the $R$. sanguineus group may inhabit different ecological zones in the Sudan. Thus, whereas Rhipicephalus camicasi was restricted to northern Sudan, Rhipicephalus turanicus and Rhipicephalus guilhoni occurred in southern Sudan, and Rhipicephalus bergeoni occurred only in eastern Sudan adjacent to the sub-highland ecological zone of Ethiopia (Jongejan et al. 1987). Rhipicephalus sanguineus group was found primarily on sheep in eastern Sudan (Karrar et al. 1963) and in the semiarid and savannah zones in Kordofan in western Sudan (Osman et al. 1982). Rhipicephalus sanguineus group ticks collected in River Nile province may represent different species (most probably $R$. camicasi) with different ecological and biological properties.

Rhipicephalus simus (or more correctly, the R. simus group [Horak \& Walker 2003]) only occasionally infests sheep in Sudan (Karrar et al. 1963; Osman et al. 1982) whereas $R$. e. evertsi is more common on this host (Karrar et al. 1963). Both species were found on sheep in the present study area but in low numbers.

Hyalomma dromedarii was collected only on two animals in the present investigation. Since camels are rare in agricultural areas along the Nile River in this province this may contribute to the rarity of this species on sheep. However, similar findings were reported by Karrar et al. (1963) in eastern Sudan, where camels are abundant indicating that sheep are not a preferred host for this species.

In this study, the adults of $\mathrm{H}$. a. anatolicum were active throughout the year. However, the results indicate that there are some critical months during which development ceased or was very low. The adults were abundant on sheep during the period 
between September and March (late rainy season to winter) when the average monthly temperature ranged between $21^{\circ} \mathrm{C}$ and $36^{\circ} \mathrm{C}$. On the other hand, the number of adults ticks was very low during the hot months (April to August) when the maximum temperature exceeded $40^{\circ} \mathrm{C}$ and the average monthly temperature ranged between $31.5^{\circ} \mathrm{C}$ and $36.5^{\circ} \mathrm{C}$. This high temperature in combination with low relative humidity generally below $50 \%$ may cause mortality or suppress tick activity. This is especially true for the immature ticks that completely disappeared during the same period, put resumed activity when temperatures decreased (September to March).

Similar results were reported by Mohamed (1999) in Khartoum Province in the semi-arid zone. Hyalomma a. anatolicum adults and immatures were collected on sheep throughout the year except during December and January (winter) when adult ticks disappeared, and during January when no immatures were found (Mohamed 1999).

It appears from the present study that there are two peaks of tick activity, one in January and one in March. However, during the second peak that occurred in March no immatures were found as a result of the high environmental temperature during this time of the year.

El Ghali \& El Hussein (1995) reported the year-round occurrence of clinical cases of malignant ovine theileriosis with outbreaks occurring annually (Ahmed, El Hussein, El Ghali \& Salih 2003), indicating endemic instability of the disease in River Nile Province. The generally low adult $H$. a. anatolicum burden and the great fluctuation in their numbers reported here, in addition to their low infection rate $(6.2 \%)$ with the parasite Theileria lestoquardi (Ahmed et al. 2003) and the relative inefficiency of immature stages (nymphs) in transmitting the infection (HooshmandRad \& Hawa 1973) may not ensure continuous and high transmission rates that are required to create endemic stability in this area. Hence, susceptible populations of sheep are always available for the disease to appear.

Discussion on the seasonal dynamics of $R$. sanguineus group is impossible because the numbers encountered during the present study were too low. However, in this study, few specimens or none were reported during most of the year except for the marked increase during March (1997). Osman 1978, Osman et al. (1982), Jongejan et al. (1987) and Mohamed (1999) reported a marked increase in the population of this tick during and after the rainy season (June to October) in Darfur, Kordofan, Blue and White Nile, and Khartoum states in the Sudan.

\section{ACKNOWLEDGEMENTS}

The authors express their gratitude to Prof. Frans Jongejan, Utrecht University for valuable comments on the manuscript. This paper is published by the kind permission of the Director of Animal Resources Research Cooperation, Sudan.

\section{REFERENCES}

AHEMD, B.M., EL HUSSEIN, A.M., EL GHALI, A. \& SALIH, D.A. 2003. Some studies on the epidemiology of malignant ovine theileriosis in River Nile State, Northern Sudan. Journal of Animal and Veterinary Advances, 2:681-685.

ANDERSON, F.W. 1948. The vegetation of the Sudan, in Agriculture in the Sudan. Oxford: Oxford University Press.

ANONYMOUS. 2002. Annual report. Department of Planning and Economics. Federal Ministry of Animal Resources and Fishers, Khartoum Sudan.

EL GHALI, A. \& EL HUSSEIN, A.M. 1995. Diseases of livestock in Eddamer Province: A two year retrospective study. Sudan Journal of Veterinary Science and Animal Husbandry, 34: 37-45.

EL IMAM, A.H. 2003. Ecological studies on ticks (Acari: Ixodidae) infesting cattle in Kosti Province, Sudan. Sudan Journal of Veterinary Science and Animal Husbandry, 42:62-71.

HARRISON, M.N. \& JACKSON, J.K. 1958. Ecological classification of the vegetation of the Sudan. Ministry of Agriculture, Forests Bulletin Sudan, 2.

HOOGSTRAAL, H. 1956. African Ixodoidea I. Ticks of the Sudan (with special reference to Equatorial Province and with preliminary review of genera Boophilus, Margaropus and Hyalomma) Washington DC: US Navy.

HOOSHMAND-RAD, P. \& HAWA, N.J. 1973. Transmission of Theileria hirci in sheep by Hyalomma anatolicum anatolicum. Bulletin of Animal Health and Production, 5:103-109.

HORAK, I.G. \& WALKER, J.B. 2003. The taxonomy, distribution and biology of Rhipicephalus mushsame, $R$. praetextatus, $R$. simus and $R$. gertrudae. Sudan Journal of Veterinary Science and Animal Husbandry, 42:100-104.

JONGEJAN, F., ZIVKOVIC, D., PEGRAM, R.G., TATCHELL, R.J., FISON T., LATIF, A. \& PAINE, G. 1987. Ticks (Acari: Ixodidae) of the Blue and White Nile ecosystems in the Sudan with particular reference to the Rhipicephalus sanguineus group. Experimental and Applied Acarology, 3:331346.

KARRAR, G., KAISER, M.N. \& HOOGSTRAAL, H. 1963. Ecology and host-relationships of ticks (Ixodoidea) infesting domestic animals in Kassala Province, Sudan, with special reference to Ambylomma lepidum Donitz. Bulletin of Entomological Research, 54:509-522.

MOHAMED, I.A. 1999. Pathogenicity of Theileria lestoquardi in susceptible sheep under laboratory conditions. M.V.Sc. thesis, University of Khartoum.

OSMAN, A.M. 1997. Ticks infesting sheep and goats in the Sudan. Parasitologia, 39:139-1482.

OSMAN, O.M. 1978. Preliminary notes on the distribution of ticks (Acarina. Ixodidae) in Darfour Province, Sudan. Bulletin of Animal Health and Production in Africa, 26:329-333.

OSMAN, O.M., EL HUSSEIN, A.M., AHMED, N., \& ABDULLA, H.S. 1982. Ecological studies on ticks (Acari: Ixodidae) of Kordofan region, Sudan. Bulletin of Animal Health and Production, 14:151-154. 